\title{
Accuracy of plasma sTREM-1 for sepsis diagnosis in systemic inflammatory patients: a systematic review and meta-analysis
}

\author{
Youping $\mathrm{Wu}^{\dagger}$, Fei Wang ${ }^{\dagger}$, Xiaohua Fan ${ }^{\dagger}$, Rui Bao, Lulong Bo, Jinbao Li ${ }^{*}$ and Xiaoming Deng ${ }^{*}$
}

\begin{abstract}
Introduction: Early diagnosis of sepsis is vital to the clinical course and outcome of septic patients. Recently, soluble triggering receptor expressed on myeloid cells-1 (STREM-1) appears to be a potential marker of infection. The objective of this systematic review and meta-analysis was to evaluate the accuracy of plasma sTREM-1 for sepsis diagnosis in systemic inflammatory patients.

Methods: A systematic literature search of PubMed, Embase and Cochrane Central Register of Controlled Trials was performed using specific search terms (up to 15 October 2012). Studies were included if they assessed the accuracy of plasma sTREM-1 for sepsis diagnosis in adult patients with systemic inflammatory response syndrome (SIRS) and provided sufficient information to construct a $2 \times 2$ contingency table.

Results: Eleven studies with a total of 1,795 patients were included. The pooled sensitivity and specificity was 79\% (95\% confidence interval (Cl), 65 to 89) and $80 \%(95 \% \mathrm{Cl}, 69$ to 88), respectively. The positive likelihood ratio, negative likelihood ratio and diagnostic odds ratio were $4.0(95 \% \mathrm{Cl}, 2.4$ to 6.9$), 0.26(95 \% \mathrm{Cl}, 0.14$ to 0.48$)$, and 16 ( $95 \% \mathrm{Cl}, 5$ to 46), respectively. The area under the curve of the summary receiver operator characteristic was 0.87 ( $95 \% \mathrm{Cl}, 0.84$ to 0.89 ). Meta-regression analysis suggested that patient sample size and assay method were the main sources of heterogeneity. Publication bias was suggested by an asymmetrical funnel plot $(P=0.02)$.
\end{abstract}

Conclusions: The present meta-analysis showed that plasma sTREM-1 had a moderate diagnostic performance in differentiating sepsis from SIRS. Accordingly, plasma sTREM-1 as a single marker was not sufficient for sepsis diagnosis in systemic inflammatory patients.

\section{Introduction}

Sepsis is a life-threatening complication of infection and the most common cause of death in intensive care units (ICU) [1]. Delay in diagnosis and treatment often results in rapid progression to circulatory collapse, multiple organ failure and eventual death [2]. Therefore, accurate and timely diagnosis of sepsis will limit morbidity, reduce costs and improve patients' outcome [3-5].

Diagnosis of sepsis is based on systemic inflammatory response syndrome (SIRS) in the presence of a known infection. SIRS is very common in critically ill patients, being found in various conditions, including trauma, surgery and pancreatitis [6,7]. Microbiological culture as

\footnotetext{
*Correspondence: lijinbaoshanghai@163.com; deng_x@yahoo.com † Contributed equally

Department of Anesthesiology and Intensive Care, Changhai Hospital Second Military Medical University, Shanghai, 200433, China
}

a gold standard is used to distinguish sepsis from noninfectious conditions. However, this method lacks sensitivity, and there is often a substantial time delay. Thus, there is an urgent need for a fast, simple and accurate method to enhance sepsis diagnosis.

The triggering receptor expressed on myeloid cells-1 (TREM-1) was a recently discovered member of the immunoglobulin superfamily, expression of which on phagocytes was up-regulated by exposure to bacteria and fungi [8]. TREM-1 mediated the acute inflammatory response to microbial products. A soluble form of TREM-1 (sTREM-1) is released from the activated phagocytes and can be found in body fluids, such as plasma [9], pleural fluid [10], bronchoalveolar lavage fluid [11], urine [12] and cerebrospinal fluid [13]. Thus, sTREM-1 may act as a potential biomarker of bacterial infection $[14,15]$. Recently, several studies have been performed to 
investigate the role of plasma sTREM-1 in differentiating sepsis from non-infectious SIRS in different settings [9,16-25]. Due to the limited patient sample size recruited in the individual studies, we aimed to conduct a systematic review and meta-analysis to assess the role of plasma sTREM-1 for sepsis diagnosis in adult patients with SIRS.

\section{Materials and methods}

This systematic review and meta-analysis was performed according to the guidelines of Meta-analysis of Observational Studies in Epidemiology [26].

\section{Search strategy}

PubMed, Embase and Cochrane Controlled Clinical Trials Register Database (up to 20 June 2012) were searched by using Exploded Medical Subject Headings and the appropriate corresponding keywords, "triggering receptor expressed on myeloid cells-1", "soluble triggering receptor expressed on myeloid cells-1", "TREM-1", "sTREM-1". We updated the literature search of the above electronic databases on 15 October 2012 to find as many eligible studies as possible. No language restriction was used. Further searches were performed by checking the reference lists from primary and review articles, and manually reviewing abstract booklets and conference proceedings. The authors were contacted for study details if needed.

\section{Eligibility criteria and study selection}

Studies were included if they assessed the accuracy of plasma sTREM-1 for sepsis diagnosis in adult patients with SIRS and provided sufficient information to construct a 2 X 2 contingency table. Two reviewers independently judged study eligibility when screening the citations. Disagreements were resolved by consensus. Agreement regarding study inclusion was assessed using the Cohen $\mathrm{K}$ statistic [27].

\section{Data extraction}

Two reviewers independently abstracted data in each study to obtain information on the year of publication, country of origin, clinical setting, sample size, patients' demographics, sTREM-1 test methods, diagnostic cutoff points, sensitivity, specificity and methodological quality. Each reviewer extracted the data to construct a $2 \mathrm{X} 2$ contingency table.

\section{Definitions}

Sepsis was defined according to the criteria proposed by the American College of Chest Physicians/Society of Critical Care Medicine as the presence of an infection complicated by SIRS [28]. Patients included in the septic group had either microbiologically (culture-proven) or clinically diagnosed sepsis, whereas the other patients were included in the non-infectious SIRS group.

\section{Quality assessment}

The methodological quality of each study was graded independently by two reviewers with the Quality Assessment of Diagnostic Accuracy Studies (QUADAS) tool, a validated tool for the quality assessment of diagnostic accuracy studies [29]. Furthermore, studies were grouped according to Sackett and Haynes' [30] classification of diagnostic studies. In this classification, phase 1 studies are those that compare the difference in test results between patients with the target disorder and healthy individuals. Phase 2 studies are those that examine how the index test discriminates between patients with and without the target disorder. Phase 3 studies are those that assess the test's real-life performance in patients suspected of having the disorder.

\section{Statistical analysis}

The diagnostic meta-analysis was performed using a bivariate meta-analysis model [31] to calculate the pooled sensitivity, specificity, positive/negative likelihood ratios, and diagnostic odds ratio (DOR). The summary receiver operator characteristic (SROC) curve that plotted sensitivity versus specificity was constructed to plot the individual and summary points of sensitivity and specificity [32]. Furthermore, around the pooled estimate, we also plotted a $95 \%$ confidence region and a 95\% prediction region to illustrate the precision with which the pooled value was estimated (confidence ellipse of a mean) and to show the amount of between study variation (prediction ellipse; the likely range of values for a new study). The presence of statistical between-study heterogeneity was assessed by the $\mathrm{I}^{2}$ test [33]. Values of 25,50 and $75 \%$ for the $\mathrm{I}^{2}$ test were regarded as indicative of low, moderate and high statistical heterogeneity, respectively. Meta-regression analysis using a bivariate model was performed in order to find the effect of potentially confounding covariates. Each covariate had a fixed effect when added to the bivariate model and associated with logit(sensitivity) and/or logit (specificity) [34]. Publication bias through small study effects was assessed with a regression test on the diagnostic odds ratio [35,36]. A $P$-value $<0.05$ was considered as indicative of statistical significance. Stata intercooled version 10.1 (StataCorp, College Station, TX, USA) was used for all statistical analyses.

\section{Results}

\section{Study characteristics}

The initial search yielded 664 citations, of which 15 publications dealing with STREM-1 for sepsis diagnosis were considered as potentially suitable for inclusion. 
After full-text review, seven studies were excluded: three studies were excluded because the reviewers could not generate a 2 X 2 contingency table [37-39], one was excluded because it detected TREM-1 mRNA not sTREM-1 [40], two were excluded because it detected sTREM-1 in bronchoalveolar lavage fluid [41] or urine [12], and one was excluded because it targeted on neonates [42]. Three studies were included in the updated search (15 October 2012) [23-25]. Totally, 11 studies were included for the pooled analysis [9,16-25] (Figure 1). The Cohen $\mathrm{K}$ statistic for agreement on study inclusion was 0.92 .

A total of 1,795 patients were included, comprising 933 patients from ICU in eight studies [9,18-21,23-25], and

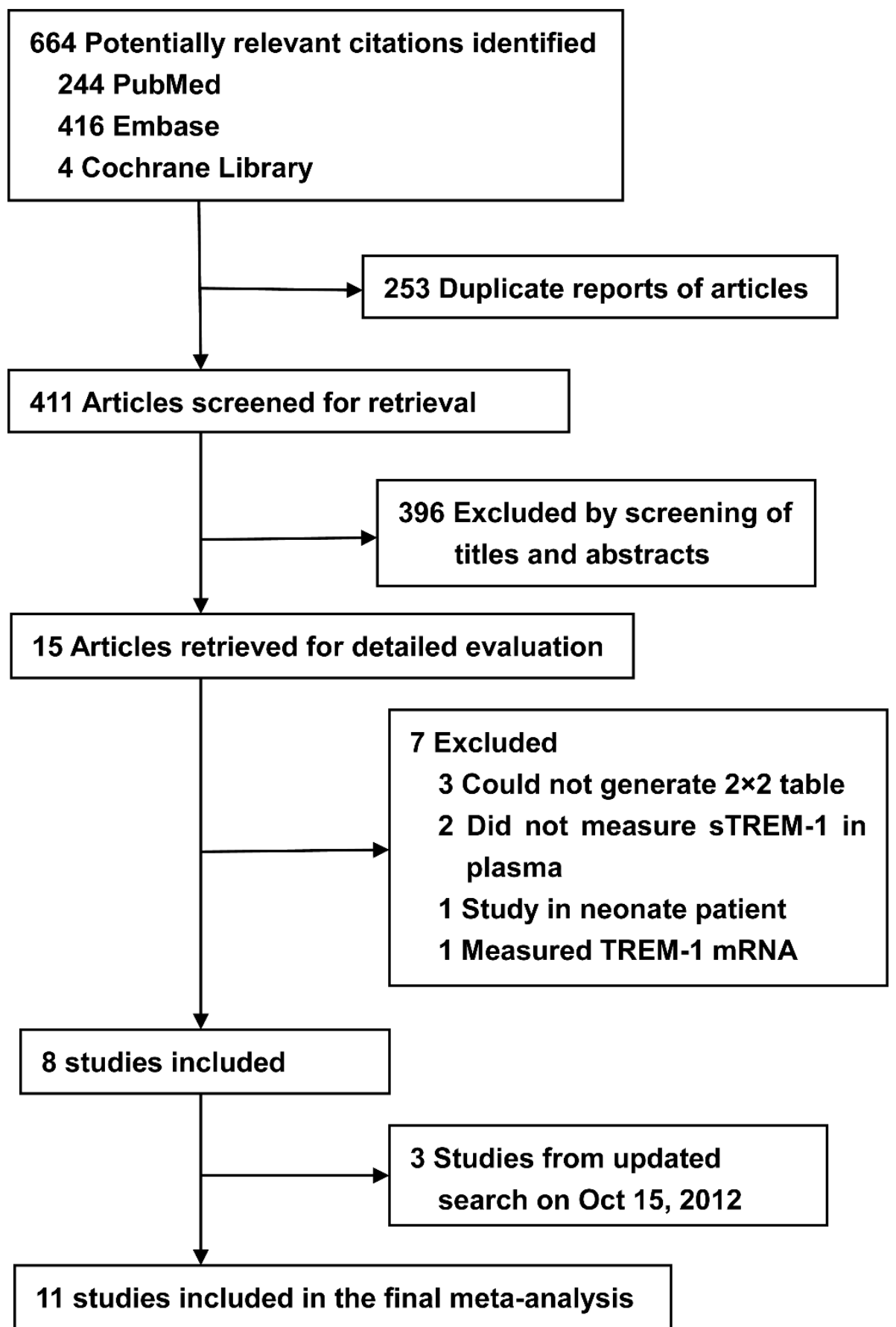

Figure 1 Study identification, inclusion, and exclusion for meta-analysis. Flow-chart of study selection. 
862 patients from emergency departments in three studies $[16,17,22]$. Mean age varied from 31 to 69 years and the proportion of male ranged from $48 \%$ to $77 \%$. The selected studies included a wide case mix, including trauma, medical and surgical illnesses. Among 1,795 patients included, SIRS criteria were fulfilled in 1,723 patients, including 1,076 septic patients and 647 non- infectious SIRS patients. Four studies recruited a group of well-matched (age and sex) patients without SIRS (10 patients in Soud et al.'s [16], 37 patients in Barati et al.'s [19], 10 patients in Giamarellos et al.'s [21], and 15 patients in Rivera et al.'s [20]) as control, and two studies [16,21] included the control patients as well as non-infectious SIRS patients in the non-septic group in a 2 X 2 contingency table when analyzing the diagnostic performance (that is, sensitivity and specificity) of sTREM-1 for sepsis. The prevalence of sepsis across studies ranged from $27 \%$ to $73 \%$. To measure plasma sTREM-1 level, enzyme-linked immunosorbent assay (ELISA) was used in 10 studies, and Luminex multiplex assay in the 1 remaining study [22]. Among the included studies, the optimal cut-off point was retrospectively determined based on the receiver operating characteristic (ROC) curve and varied greatly, from $40 \mathrm{pg} / \mathrm{ml}$ to $755 \mathrm{pg} / \mathrm{ml}$ (ELISA method). Details of the included studies were shown in Table 1.

\section{Quality assessment}

Studies were grouped according to Sackett and Haynes' classification for diagnostic studies: two were phase 2 studies (group 1) [16,21] and nine phase 3 studies (group 2) [9,17-20,22-25]. All the included studies fulfilled the requirements of acceptable reference standard, partial verification bias avoided, differential verification bias avoided, incorporation bias avoided, detailed description of index test, blinding of investigators to reference, uninterpretable results reported and withdrawals explained. Nine studies [9,17-20,22-25] recruited a representative spectrum of patients and 10 studies [9,16-24] clearly described the inclusion criteria. Disease progression bias was avoided in five studies $[9,17,19,24,25]$. Eight studies [9,17-20,22,24,25] fulfilled the requirement of blinding of investigators to index test. All except one [19] described in detail the reference standard and clinical data. The results of the methodological assessment for the included studies were summarized in Figure 2.

\section{Quantitative data synthesis}

The pooled sensitivity and specificity of all studies combined was 79\% (95\% confidence interval (CI), 65 to 89) and $80 \%$ (95\% CI, 69 to 88), respectively (Figure 3). The pooled positive likelihood ratio (PLR) was 4.0 (95\% CI, 2.4 to 6.9 ) and the pooled negative likelihood ratio (NLR) was 0.26 (95\% CI, 0.14 to 0.48 ). The area under the ROC curve was 0.87 (95\% CI, 0.84 to 0.89 ) and the DOR was
16 (95\% CI, 5 to 46), indicating a moderate diagnostic accuracy (Figure 4). The post-test probabilities based on various pre-test probabilities were illustrated using a Fagan nomogram (Figure 5).

Among the included studies, eight were conducted in the ICU and three in the emergency department. The pooled sensitivity and specificity was 78\% (95\% CI, 64 to 93) and $84 \%$ (95\% CI, 76 to 93) in ICU patients, and $83 \%$ (95\% CI, 63 to 100$)$ and $68 \%$ (95\% CI, 47 to 88 ) in patients from the emergency department. Nine studies [9,17-20,22-25] classified as phase 3 studies examined the diagnostic performance of plasma sTREM-1 for sepsis among SIRS patients suspected of infection, and the pooled sensitivity and specificity was 79\% (95\% CI, 66 to 92) and 76\% (95\% CI, 66 to 87), respectively. Given that Gamez et al.'s study [17] accounted for 35\% $(631 / 1,795)$ of the total sample size, sensitivity analysis without this study was conducted and the pooled sensitivity and specificity of the remaining 10 studies was $81 \%$ (95\% CI, 70 to 92 ) and $82 \%$ (95\% CI, 73 to 91$)$

\section{Investigation of heterogeneity}

The between study variability (that is, heterogeneity) beyond what could be expected by sampling error was high both for sensitivity (with an $\mathrm{I}^{2}$ of $95.0 \%$ ) and for specificity (with an $\mathrm{I}^{2}$ of $92.7 \%$ ). The bivariate model analysis revealed that the heterogeneity was only partly (15\%) explained by the threshold effect where variations in sensitivity and specificity were related to differences in the cut-off points of sTREM-1 in the included studies.

The source of heterogeneity was explored by univariate meta-regression analysis. Assay method, clinical setting, quality assessment, patient sample size and sepsis prevalence were used as covariates. By making each covariate associate with logit(sensitivity) or logit(specificity), metaregression analysis showed that sepsis prevalence significantly accounted for the heterogeneity for sensitivity, and assay method and clinical setting significantly accounted for the heterogeneity for specificity (Figure 6). When exploring the source of heterogeneity jointly by making each covariate associate with logit(sensitivity) and logit (specificity), meta-regression analysis showed that patient sample size and assay method were the main sources of heterogeneity. Subgroup analysis by patient sample size showed that in the five studies $[9,16,20,21,24]$ with small sample size, the pooled sensitivity and specificity was $89 \%$ (95\% CI, 80 to 98 ) and $91 \%$ (95\% CI, 84 to 97) respectively, and in the other six studies [17-19,22,23,25] with large sample size, the pooled sensitivity and specificity was $68 \%$ (95\% CI, 52 to 84) and 69\% (95\% CI, 58 to 81), respectively. Subgroup analysis by sTREM-1 assay method showed that Kofoed et al.'s study [22] using the Luminex multiplex assay had $83 \%$ sensitivity (95\% CI, 50 to 100) 
Table 1 Summary of included studies

\begin{tabular}{|c|c|c|c|c|c|c|c|c|c|c|c|}
\hline Study year & Country & Setting & SIRS patients & Control patients & $\begin{array}{l}\text { Mean age } \\
\text { (year) }\end{array}$ & Assay method & $\begin{array}{l}\text { Optimal } \\
\text { timing }\end{array}$ & $\begin{array}{l}\text { Cut-off } \\
\text { (pg/ml) }\end{array}$ & $\begin{array}{l}\text { Sensitivity/ } \\
\text { specificity (\%) }\end{array}$ & AUC & $\begin{array}{l}\text { Sepsis } \\
\text { prevalence (\%) }\end{array}$ \\
\hline \multicolumn{12}{|l|}{ Group 1 studies } \\
\hline $\begin{array}{l}\text { Giamarellos } 2008 \\
\text { [21] }\end{array}$ & Greece & ICU & $\begin{array}{l}79 \text { trauma patients with } \\
\text { all criteria: (a) older than } \\
18 \text { years; (b) ISS greater } \\
\text { than 25; (c) signs of SIRS }\end{array}$ & $\begin{array}{l}10 \text { trauma patients } \\
\text { with ISS greater } \\
\text { than } 25 \text { but without } \\
\text { SIRS }\end{array}$ & $51.8 \pm 20.6$ & $\begin{array}{l}\text { ELISA (R\&D } \\
\text { Systems, } \\
\text { Minneapolis, MN) }\end{array}$ & $\begin{array}{l}\text { on } \\
\text { admission }\end{array}$ & 40 & $56.5 / 91.7$ & 0.708 & 62 \\
\hline Soud 2011 [16] & Egypt & Surgical ED & $\begin{array}{l}80 \text { trauma patients with } \\
\text { SIRS }\end{array}$ & $\begin{array}{l}10 \text { trauma patients } \\
\text { with ISS greater } \\
\text { than } 25 \text { but without } \\
\text { SIRS }\end{array}$ & 30.5 & $\begin{array}{l}\text { ELISA (R\&D } \\
\text { Systems, } \\
\text { Minneapolis, MN) }\end{array}$ & $\begin{array}{l}\text { Not } \\
\text { reported }\end{array}$ & 254 & $94.7 / 91.8$ & $\begin{array}{l}\text { Not } \\
\text { reported }\end{array}$ & 27 \\
\hline \multicolumn{12}{|l|}{ Group 2 studies } \\
\hline Barati 2010 [19] & Iran & $\begin{array}{l}\text { medical and } \\
\text { surgical ICUs }\end{array}$ & 132 patients with SIRS & $\begin{array}{l}37 \text { patients without } \\
\text { SIRS }\end{array}$ & $\begin{array}{l}\text { Not } \\
\text { reported }\end{array}$ & $\begin{array}{l}\text { ELISA (R\&D } \\
\text { Systems, } \\
\text { Minneapolis, MN) }\end{array}$ & $\begin{array}{l}\text { on } \\
\text { admission }\end{array}$ & 725 & $70 / 60$ & 0.65 & 55 \\
\hline Gamez 2011 [17] & Colombia & ED & $\begin{array}{l}631 \text { patients older than } \\
18 \text { years with any of the } \\
\text { items: 1) suspected } \\
\text { infection, 2) fever, 3) } \\
\text { delirium, or 4) acute } \\
\text { hypotension of } \\
\text { unexplained origin within } \\
24 \text { hours of ED } \\
\text { presentation }\end{array}$ & No & $\begin{array}{l}51(36 \text { to } \\
68)^{+}\end{array}$ & $\begin{array}{l}\text { ELISA (R\&D } \\
\text { Systems, } \\
\text { Minneapolis, MN) }\end{array}$ & $\begin{array}{l}\text { within } 24 \\
\text { hours after } \\
\text { admission }\end{array}$ & 135 & $60 / 59.2$ & 0.614 & 66 \\
\hline Gibot 2004 [9] & France & medical ICU & $\begin{array}{l}76 \text { patients with clinically } \\
\text { suspected infection and } \\
\text { SIRS }\end{array}$ & No & $60 \pm 15$ & $\begin{array}{l}\text { ELISA (Dako, } \\
\text { Glostrup, } \\
\text { Denmark) }\end{array}$ & $\begin{array}{l}\text { within } 12 \\
\text { hours after } \\
\text { admission }\end{array}$ & 60 & $96 / 89$ & 0.97 & 62 \\
\hline Gibot 2012 [25] & France & ICU & $\begin{array}{l}228 \text { patients with } \\
\text { clinically suspected } \\
\text { infection }\end{array}$ & No & $\begin{array}{l}\text { Not } \\
\text { reported }\end{array}$ & $\begin{array}{l}\text { ELISA (R\&D } \\
\text { Systems, } \\
\text { Minneapolis, MN) }\end{array}$ & $\begin{array}{l}\text { within } 12 \\
\text { hours after } \\
\text { admission }\end{array}$ & 755 & $54.2 / 86.6$ & 0.73 & 67 \\
\hline Kofoed 2007 [22] & Denmark & medical ED & $\begin{array}{l}151 \text { patients with } \\
\text { suspected community- } \\
\text { acquired infections and } \\
\text { SIRS }\end{array}$ & No & $\begin{array}{l}56(20 \text { to } \\
94)^{+}\end{array}$ & $\begin{array}{l}\text { Luminex } \\
\text { multiplex assay } \\
\text { (Luminex Corp., } \\
\text { Austin, TX) }\end{array}$ & $\begin{array}{l}\text { on } \\
\text { admission }\end{array}$ & 3500 & $82 / 40$ & 0.61 & 64 \\
\hline Latour 2010 [18] & Spain & $\begin{array}{l}\text { two general } \\
\text { ICU }\end{array}$ & $\begin{array}{l}114 \text { patients older than } \\
18 \text { years with SIRS }\end{array}$ & No & $\begin{array}{l}\text { Not } \\
\text { reported }\end{array}$ & $\begin{array}{l}\text { ELISA (R\&D } \\
\text { Systems, } \\
\text { Minneapolis, MN) }\end{array}$ & $\begin{array}{l}\text { within } 24 \\
\text { hours after } \\
\text { admission }\end{array}$ & 463.2 & $49 / 79$ & 0.62 & 63 \\
\hline Li 2012 [24] & China & surgical ICU & $\begin{array}{l}52 \text { patients with clinically } \\
\text { suspected infection and } \\
\text { SIRS }\end{array}$ & No & 55.7 & $\begin{array}{l}\text { ELISA (R\&D } \\
\text { Systems, } \\
\text { Minneapolis, MN) }\end{array}$ & $\begin{array}{l}\text { within } 12 \\
\text { hours after } \\
\text { admission }\end{array}$ & 73.57 & $79 / 79$ & 0.820 & 73 \\
\hline Rivera 2009 [20] & USA & surgical ICU & $\begin{array}{l}108 \text { patients with } \\
\text { clinically suspected } \\
\text { infection and SIRS }\end{array}$ & $\begin{array}{l}15 \text { trauma patients } \\
\text { with ISS greater } \\
\text { than } 25 \text { but without } \\
\text { SIRS }\end{array}$ & 35 & $\begin{array}{l}\text { ELISA (R\&D } \\
\text { Systems, } \\
\text { Minneapolis, MN) }\end{array}$ & $\begin{array}{l}\text { within } 12- \\
36 \text { hours } \\
\text { after } \\
\text { admission }\end{array}$ & 230 & $98 / 91$ & 0.97 & 60 \\
\hline Su 2012 [23] & China & $\begin{array}{l}\text { respiratory, } \\
\text { surgical and } \\
\text { emergency } \\
\text { ICUs }\end{array}$ & $\begin{array}{l}144 \text { older than } 18 \text { years } \\
\text { with new fever and SIRS }\end{array}$ & No & 54.5 & $\begin{array}{l}\text { ELISA (R\&D } \\
\text { Systems, } \\
\text { Minneapolis, MN) }\end{array}$ & $\begin{array}{l}\text { within } 24 \\
\text { hours after } \\
\text { admission }\end{array}$ & 108.9 & $83 / 81$ & 0.868 & 58 \\
\hline
\end{tabular}




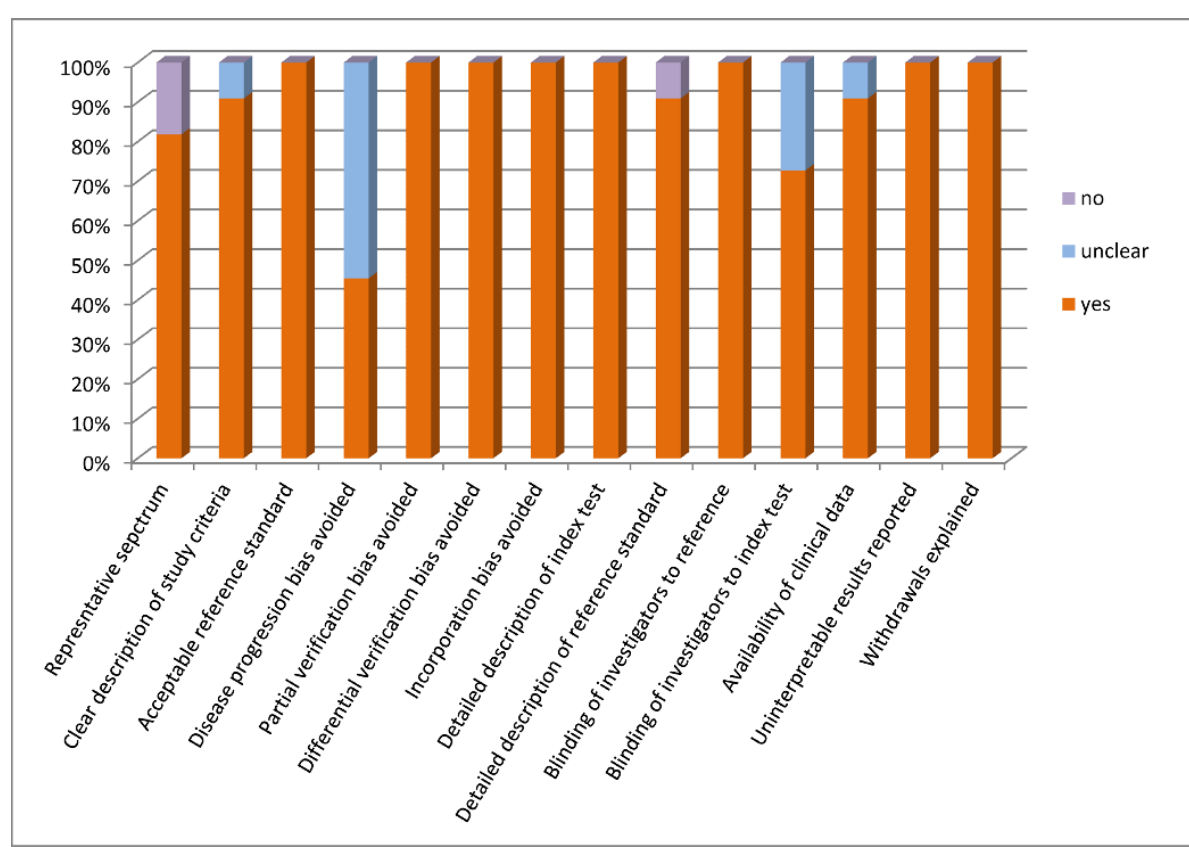

Figure 2 Proportion of Quality Assessment of Diagnostic Accuracy Studies (QUADAS) tool criteria fulfilled for included studies Proportion of all 14 Quality Assessment of Diagnostic Accuracy Studies (QUADAS) tool criteria that were fulfilled for eleven studies included in the meta-analysis.

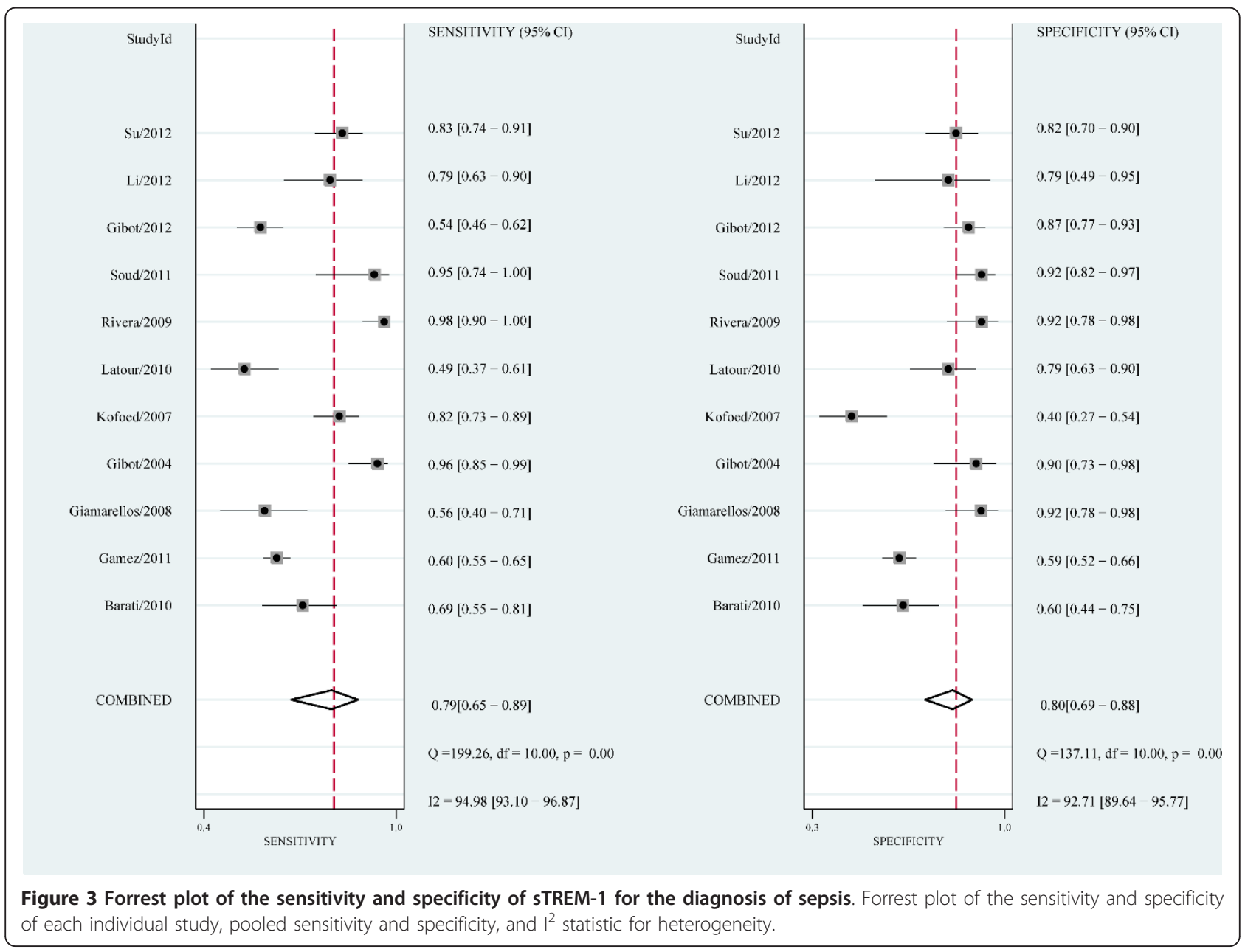




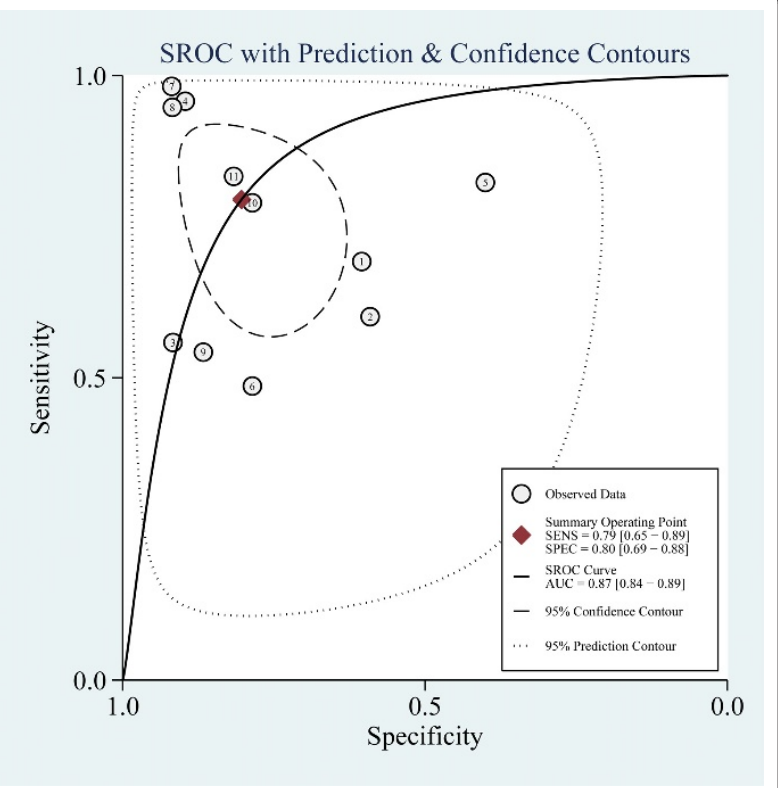

Figure 4 Summary receiver operating characteristic graph of included studies. Summary receiver operating characteristic graph with 95\% confidence region and 95\% prediction region for sTREM-1.

and $40 \%$ specificity (95\% CI, 6 to 74 ) and the other 10 studies using the ELISA had 79\% sensitivity (95\% CI, 67 to 92) and $83 \%$ pooled specificity ( $95 \%$ CI, 76 to 90 ).

\section{Evaluation of publication bias}

Deeks' funnel plot asymmetry test suggested potential publication bias $(P=0.02)$ (Figure 7).

\section{Discussion}

Early identification of infection is of vital importance to the clinical course and outcome of septic patients. An ideal marker of sepsis should be present early in the course of the disease, measurable rapidly and easily, of prognostic significance, sensitive enough to detect infection in patients with minimal host response, and specific enough to discriminate infection from other non-infectious SIRS [43].

Biological markers such as procalcitonin and CRP have been used in the diagnosis of bacterial infections $[44,45]$. However, since they are "indirect" markers of infection, their sensitivity and specificity are not $100 \%$ and vary in different patient groups and indications. TREM-1 was a recently identified molecule involved in inflammatory response. Human tissues infected with bacteria were infiltrated with neutrophils and monocytes that expressed high levels of TREM-1 $[8,46]$. TREM-1 amplifies infection-induced inflammatory response signals primarily through the mediation of adapter protein DAP12 on the cell surface [47]. sTREM-1, as the soluble form of TREM-1, released by activated phagocytes, may be a more "direct" marker of infection. In the present study, pooled analysis showed that plasma sTREM-1 seemed to have a moderate $(0.7 \leq$ AUC $<0.9)$ diagnostic accuracy for sepsis since the area under the SROC curve was 0.87 . The pooled sensitivity of plasma sTREM- 1 for the diagnosis of sepsis was $79 \%$ and the specificity was $80 \%$. With a hypothetical pretest probability of $62 \%$ and a PLR of 4.0, detecting plasma STREM-1 for sepsis diagnosis would raise the post-test probability to $87 \%$. With a NLR of 0.26 , detecting plasma sTREM-1 reduced the post-test probability to $30 \%$ (Figure 5 ), showing that application of plasma sTREM-1 test to sepsis diagnosis had a moderate value. Recently, several studies reported that plasma STREM-1 level could be elevated in noninfectious disease, such as acute pancreatitis, and noninfectious inflammation following traumatic lung contusion [48-50]. We inferred that in the non-infectious SIRS patients, sTREM-1 level was elevated, which might partly account for its moderate but not high accuracy in distinguishing septic patients from non-infectious SIRS patients. To date, none of the proposed biomarkers as a single test had sufficient (more than 90\%) sensitivity and specificity to discriminate sepsis from SIRS in critically ill adult patients. A combination of several markers appears to be a useful approach to improving accuracy in diagnosing sepsis, which was proved by a recent paper from Gibot et al. [25]. In their study, although sTREM-1, PCT and polymorphonuclear CD64 index were all found to be independent predictors of sepsis, a combination of them was shown to have a far better diagnostic performance for sepsis with the area under the ROC curve to be $97 \%$ (95\% CI, 95 to 99 ).

As a single indicator of diagnostic test performance, DOR is independent of disease prevalence. The DOR of the included studies ranged from 2.17 to 623.33 , and the pooled DOR was 16 . The disparity noticed in the included studies may result from several reasons. First, patient sample size varied in the included studies. It was suggested that small studies tend to overestimate the effect size [51] and studies based on small sample sizes may have allowed for a type II error. In the present study, meta-regression analysis showed that patient sample size significantly accounted for the heterogeneity. The pooled DOR of the five studies $[9,16,20,21,24]$ with small sample size was 90 (95\% CI, 20 to 399), higher than that of the other six studies [17-19,22,23,25] with large sample size (pooled DOR 5, 95\% CI, 3 to 9). Therefore, caution should be taken when interpreting the results. Another possible reason was different disease spectrum included. The pooled DOR of the three studies $[16,20,21]$ which enrolled trauma or injured patients was 104. (95\% CI, 9 to $1,206)$, higher than that of the remaining studies which enrolled other kinds of patient spectrum (pooled DOR 8, 95\% CI, 3 to 19). 


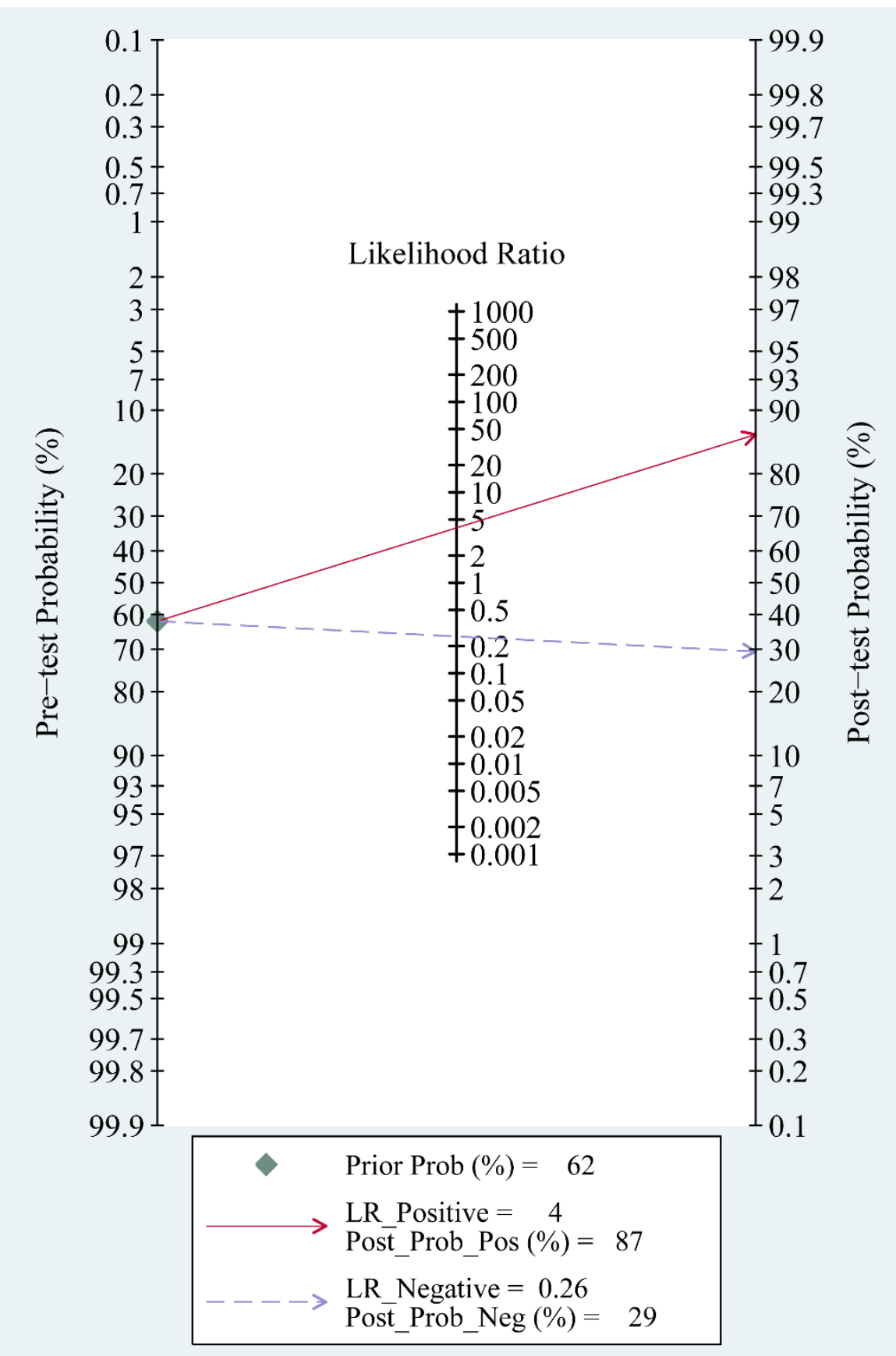

Figure 5 Fagan's nomogram for calculation of post-test probabilities. Fagan's nomogram for sTREM-1 illustrating post-test probability with a fixed pre-test probability of $62 \%$ for sepsis.

Two prior meta-analyses concluded that sTREM-1 represented a useful biological marker of bacterial infection [14] or bacterial pleural effusions [15]. The meta-analysis by Jing et al. [14] included studies across a wide range of disease spectrum, and assessed sTREM-1 level from different sample origins, including non-directed bronchial lavage fluids, pleural fluid, plasma, bronchoalveolar lavage fluid, cerebrospinal fluid and urine. The other meta-analysis by Summah et al. [15] assessed the diagnostic accuracy of sTREM-1 in the pleural fluid for bacterial pleural effusions. Being different from them, the present meta-analysis assessed the diagnostic accuracy of sTREM-1 for sepsis and focused only on the plasma level of STREM-1. 
Univariable Meta-regression \& Subgroup Analyses
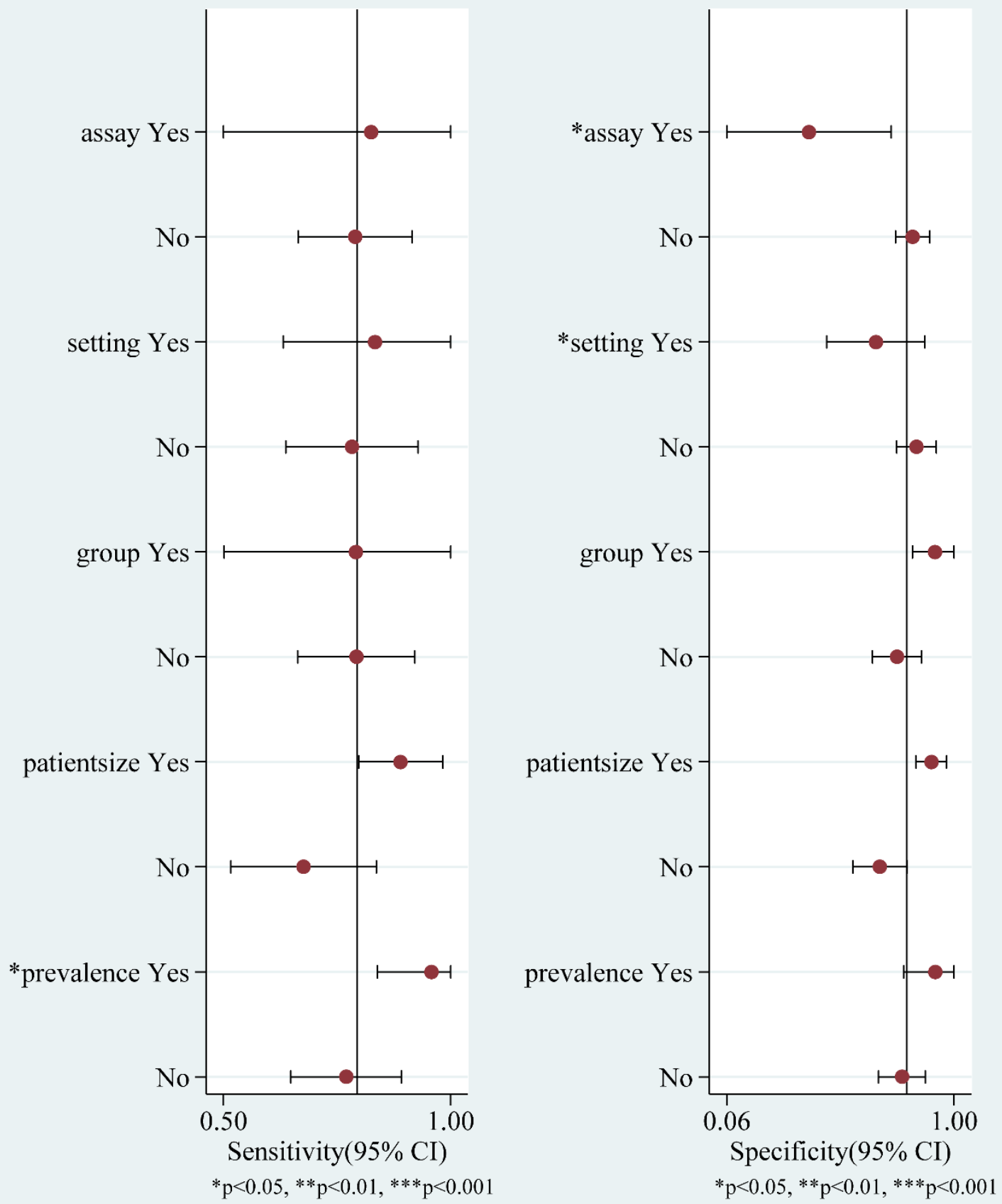

Figure 6 Univariable meta-regression and subgroup analysis

Although detecting the samples from suspected sites of infection might result in higher diagnostic accuracy than detecting the plasma sample, it is faster, easier and simpler to collect plasma samples.
The present meta-analysis had several limitations. First, although extensive literature search was conducted, the number of included studies was small. Second, in the patients who were clinically diagnosed as having sepsis 


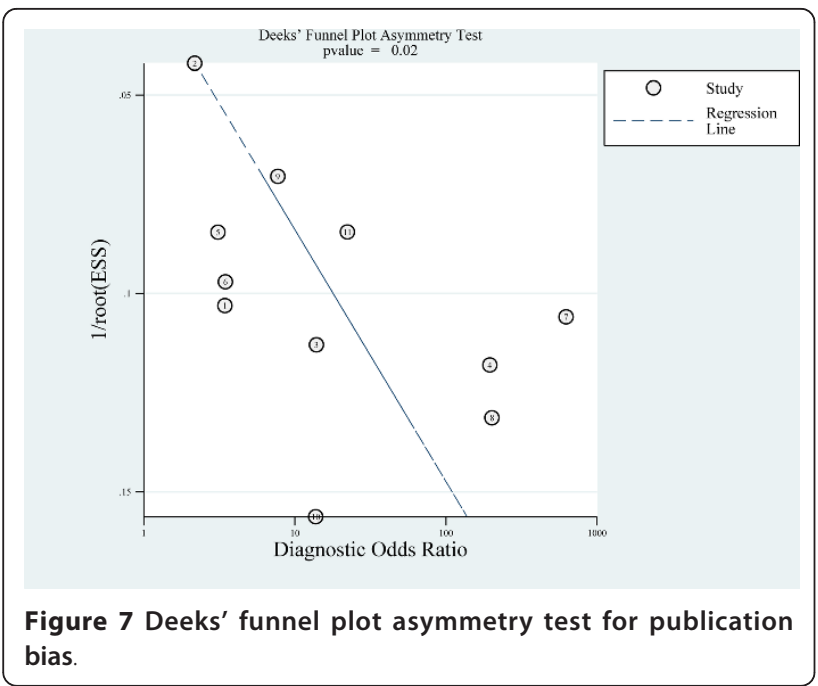

without microbiological evidence, some degree of misclassification bias may have existed. Third, several studies reported STREM-1 could reflect the severity of sepsis and predict prognosis, we didn't address this issue. Finally, we could not determine the ideal cut-off point for plasma STREM-1 test because we did not have the raw data to map out the ROC curve. To determine whether there is a single threshold or a few important thresholds, further studies with a larger number of patients are needed.

\section{Conclusions}

In summary, plasma sTREM-1 had a moderate diagnostic performance in differentiating sepsis from SIRS in adult patients. Accordingly, plasma sTREM-1 as a single marker was not sufficient for sepsis diagnosis in systemic inflammatory patients.

\section{Key messages}

- The present study showed that the pooled sensitivity and specificity of plasma sTREM-1 for sepsis diagnosis was $79 \%$ and $80 \%$, respectively. The area under the SROC curve was 0.87 .

- Plasma sTREM-1 had a moderate diagnostic performance in differentiating sepsis from SIRS in adult patients. Accordingly, as a single marker it was not sufficient for sepsis diagnosis in systemic inflammatory patients.

\footnotetext{
Abbreviations

AUC: area under the receiver operating characteristic curve; $\mathrm{Cl}$ : confidence interval; DOR: diagnostic odds ratio; ELISA: enzyme-linked immunosorbent assay; ICU: intensive care unit; NLR: negative likelihood ratio; PLR: positive likelihood ratio; QUADAS: Quality Assessment of Diagnostic Accuracy Studies; ROC: receiver operating characteristic; SIRS: systemic inflammatory response syndrome; SROC: summary receiver operator characteristic; sTREM-1: soluble triggering receptor expressed on myeloid cells-1; TREM-1: triggering receptor expressed on myeloid cells-1.
}

\section{Authors' contributions}

YW, FW, XF, JL and XD were responsible for study concept and design. YW FW and XF acquired the data. RB and LB analyzed and interpreted the data. YW, FW and XF drafted the manuscript. $J$ and XD critically revised the manuscript for important intellectual content. YW and FW performed statistical analysis. RB and LB were responsible for administrative, technical and material support. $J L$ and XD supervised the study. All authors have read and approved the manuscript for publication.

\section{Competing interests}

The authors declared that they have no competing interests.

Received: 16 August 2012 Revised: 15 November 2012

Accepted: 28 November 2012 Published: 29 November 2012

\section{References}

1. Martin GS, Mannino DM, Eaton S, Moss M: The epidemiology of sepsis in the United States from 1979 through 2000. N Engl J Med 2003, 348:1546-1554.

2. Warren HS: Strategies for the treatment of sepsis. N Engl J Med 1997, 336:952-953.

3. Kollef MH, Sherman G, Ward S, Fraser VJ: Inadequate antimicrobial treatment of infections: a risk factor for hospital mortality among critically ill patients. Chest 1999, 115:462-474.

4. Pittet D, Rangel-Frausto S, Li N, Tarara D, Costigan M, Rempe L, Jebson P, Wenzel RP: Systemic inflammatory response syndrome, sepsis, severe sepsis and septic shock: incidence, morbidities and outcomes in surgical ICU patients. Intensive Care Med 1995, 21:302-309.

5. Otero RM, Nguyen HB, Huang DT, Gaieski DF, Goyal M, Gunnerson KJ, Trzeciak S, Sherwin R, Holthaus CV, Osborn T, Rivers EP: Early goal-directed therapy in severe sepsis and septic shock revisited: concepts, controversies, and contemporary findings. Chest 2006, 130:1579-1595.

6. Rangel-Frausto MS, Pittet D, Costigan M, Hwang T, Davis CS, Wenzel RP: The natural history of the systemic inflammatory response syndrome (SIRS). A prospective study. JAMA 1995, 273:117-123.

7. Adib-Conquy M, Cavaillon JM: Stress molecules in sepsis and systemic inflammatory response syndrome. FEBS Lett 2007, 581:3723-3733.

8. Bouchon A, Dietrich J, Colonna M: Cutting edge: inflammatory responses can be triggered by TREM-1, a novel receptor expressed on neutrophils and monocytes. J Immunol 2000, 164:4991-4995.

9. Gibot S, Kolopp-Sarda MN, Béné MC, Cravoisy A, Levy B, Faure GC, Bollaert PE: Plasma level of a triggering receptor expressed on myeloid cells-1: its diagnostic accuracy in patients with suspected sepsis. Ann Intern Med 2004, 141:9-15.

10. Kim J-H, Park E-Y, Kim W-H, Park W, Jeong H-C, Lee J-H, Kim E-K: Soluble triggering receptor expressed on myeloid cells-1: role in the diagnosis of pleural effusions. Tuberc Respir Dis 2007, 62:290-298.

11. Gibot S, Cravoisy A, Levy B, Béné MC, Faure G, Bollaert PE: Soluble triggering receptor expressed on myeloid cells and the diagnosis of pneumonia. N Engl J Med 2004, 350:451-458.

12. Su LX, Feng L, Zhang J, Xiao YJ, Jia YH, Yan P, Feng D, Xie LX: Diagnostic value of urine sTREM-1 for sepsis and relevant acute kidney injuries: a prospective study. Crit Care 2011, 15:R250.

13. Determann RM, Weisfelt M, de Gans J, van der Ende A, Schultz MJ, van de Beek D: Soluble triggering receptor expressed on myeloid cells 1: a biomarker for bacterial meningitis. Intensive Care Med 2006, 32:1243-1247.

14. Jiyong J, Tiancha $\mathrm{H}$, Wei $\mathrm{C}$, Huahao S: Diagnostic value of the soluble triggering receptor expressed on myeloid cells-1 in bacterial infection: a meta-analysis. Intensive Care Med 2009, 35:587-595.

15. Summah $H$, Tao LL, Zhu YG, Jiang HN, Qu JM: Pleural fluid soluble triggering receptor expressed on myeloid cells- 1 as a marker of bacterial infection: a meta-analysis. BMC Infect Dis 2011, 11:280.

16. Soud DEM, Amin OAl, Amin AAI: New era "soluble triggering receptor expressed on myeloid cells-I" as a marker for early detection of infection in trauma patients. Egypt J Anaesthesia 2011, 27:267-272.

17. Gamez-Diaz LY, Enriquez LE, Matute JD, Velasquez S, Gomez ID, Toro F, Ospina S, Bedoya V, Arango CM, Valencia ML, De La Rosa G, Gomez Cl, Garcia A, Patino PJ, Jaimes FA: Diagnostic accuracy of HMGB-1, sTREM-1, and CD64 as markers of sepsis in patients recently admitted to the emergency department. Acad Emerg Med 2011, 18:807-815. 
18. Latour-Perez J, Alcala-Lopez A, Garcia-Garcia MA, Sanchez-Hernandez JF, Abad-Terrado C, Viedma-Contreras JA, Masia M, Gonzalez-Tejera M, ArizoLeon D, Porcar MJ, Bonilla-Rovira F, Gutierrez F: Diagnostic accuracy of STREM-1 to identify infection in critically ill patients with systemic inflammatory response syndrome. Clin Biochem 2010, 43:720-724.

19. Barati M, Bashar FR, Shahrami R, Zadeh MH, Taher MT, Nojomi M: Soluble triggering receptor expressed on myeloid cells 1 and the diagnosis of sepsis. J Crit Care 2010, 25:362 e361-366.

20. Rivera-Chavez FA, Minei JP: Soluble triggering receptor expressed on myeloid cells-1 is an early marker of infection in the surgical intensive care unit. Surg Infect 2009, 10:435-439.

21. Giamarellos-Bourboulis EJ, Mouktaroudi M, Tsaganos T, Koutoukas P, Spyridaki E, Pelekanou A, Kotzampassi K: Evidence for the participation of soluble triggering receptor expressed on myeloid cells- 1 in the systemic inflammatory response syndrome after multiple trauma. J Trauma 2008, 65:1385-1390.

22. Kofoed K, Andersen O, Kronborg G, Tvede M, Petersen J, Eugen-Olsen J, Larsen K: Use of plasma C-reactive protein, procalcitonin, neutrophils, macrophage migration inhibitory factor, soluble urokinase-type plasminogen activator receptor, and soluble triggering receptor expressed on myeloid cells- 1 in combination to diagnose infections: a prospective study. Crit Care 2007, 11:R38.

23. Su L, Han B, Liu C, Liang L, Jiang Z, Deng J, Yan P, Jia Y, Feng D, Xie L: Value of soluble TREM-1, procalcitonin, and C-reactive protein serum levels as biomarkers for detecting bacteremia among sepsis patients with new fever in intensive care units: a prospective cohort study. BMC Infect Dis 2012, 12:157.

24. Li L, Zhu Z, Chen J, Ouyang B, Chen M, Guan X: Diagnostic value of soluble triggering receptor expressed on myeloid cells-1 in critically ill, postoperative patients with suspected sepsis. Am J Med Sci 2012.

25. Gibot S, Béné MC, Noel R, Massin F, Guy J, Cravoisy A, Barraud D, De Carvalho Bittencourt M, Quenot JP, Bollaert PE, Faure G, Charles PE: Combination biomarkers to diagnose sepsis in the critically ill patient. Am J Respir Crit Care Med 2012, 186:65-71.

26. Stroup DF, Berlin JA, Morton SC, Olkin I, Williamson GD, Rennie D, Moher D, Becker BJ, Sipe TA, Thacker SB: Meta-analysis of observational studies in epidemiology: a proposal for reporting. Meta-analysis Of Observational Studies in Epidemiology (MOOSE) group. JAMA 2000, 283:2008-2012

27. Landis JR, Koch GG: The measurement of observer agreement for categorical data. Biometrics 1977, 33:159-174.

28. Levy MM, Fink MP, Marshall JC, Abraham E, Angus D, Cook D, Cohen J, Opal SM, Vincent JL, Ramsay G: 2001 SCCM/ESICM/ACCP/ATS/SIS International Sepsis Definitions Conference. Crit Care Med 2003, 31:1250-1256

29. Whiting P, Rutjes AW, Reitsma JB, Bossuyt PM, Kleijnen J: The development of QUADAS: a tool for the quality assessment of studies of diagnostic accuracy included in systematic reviews. BMC Med Res Methodol 2003, $3: 25$.

30. Sackett DL, Haynes RB: The architecture of diagnostic research. BMJ 2002, 324:539-541

31. Reitsma JB, Glas AS, Rutjes AW, Scholten RJ, Bossuyt PM, Zwinderman AH: Bivariate analysis of sensitivity and specificity produces informative summary measures in diagnostic reviews. J Clin Epidemiol 2005, 58:982-990.

32. Moses LE, Shapiro D, Littenberg B: Combining independent studies of a diagnostic test into a summary ROC curve: data-analytic approaches and some additional considerations. Stat Med 1993, 12:1293-1316.

33. Bowden J, Tierney JF, Copas AJ, Burdett S: Quantifying, displaying and accounting for heterogeneity in the meta-analysis of RCTs using standard and generalised Q statistics. BMC Med Res Methodol 2011, 11:41.

34. Macaskill P, Gatsonis C, Deeks JJ, Harbord RM, Takwoingi Y: Chapter 10 Analysing and presenting results. In Cochrane Handbook for Systematic Reviews of Diagnostic Test Accuracy. Version 1.0. Edited by: Deeks JJ, Bossuyt PM, Gatsonis C. Oxford, UK: The Cochrane Collaboration; 2010:

35. Dinnes J, Deeks J, Kirby J, Roderick P: A methodological review of how heterogeneity has been examined in systematic reviews of diagnostic test accuracy. Health Technol Assess 2005, 9:1-113, iii.

36. Rucker G, Carpenter JR, Schwarzer G: Detecting and adjusting for smallstudy effects in meta-analysis. Biom J 2011, 53:351-368.
37. Li J, Birkenheuer AJ, Marr HS, Levy MG, Yoder JA, Nordone SK: Expression and function of triggering receptor expressed on myeloid cells-1 (TREM1) on canine neutrophils. Dev Comp Immunol 2011, 35:872-880.

38. Bopp C, Hofer S, Bouchon A, Zimmermann JB, Martin E, Weigand MA: Soluble TREM-1 is not suitable for distinguishing between systemic inflammatory response syndrome and sepsis survivors and nonsurvivors in the early stage of acute inflammation. Eur J Anaesthesiol 2009, 26:504-507.

39. Hong-xia Wang, Chen B: Diagnostic role of soluble triggering receptor expressed on myeloid cell-1 in patients with sepsis. World J Emerg Med 2011, 2:190-194.

40. How CK, Chern CH, Wu MF, Wang LM, Huang Cl, Lee CH, Hsieh SL: Expression of the triggering receptor expressed on myeloid cells-1 mRNA in a heterogeneous infected population. Int J Clin Pract 2009, 63:126-133.

41. Gibot S, Cravoisy A, Dupays R, Barraud D, Nace L, Levy B, Bollaert PE: Combined measurement of procalcitonin and soluble TREM- 1 in the diagnosis of nosocomial sepsis. Scand J Infect Dis 2007, 39:604-608.

42. Sarafidis K, Soubasi-Griva V, Piretzi K, Thomaidou A, Agakidou E, Taparkou A, Diamanti E, Drossou-Agakidou V: Diagnostic utility of elevated serum soluble triggering receptor expressed on myeloid cells (sTREM)-1 in infected neonates. Intensive Care Med 2010, 36:864-868.

43. Carlet J: Rapid diagnostic methods in the detection of sepsis. Infect Dis Clin North Am 1999, 13:483-494, xi.

44. Mitaka C: Clinical laboratory differentiation of infectious versus noninfectious systemic inflammatory response syndrome. Clin Chim Acta 2005, 351:17-29

45. Kibe S, Adams K, Barlow G: Diagnostic and prognostic biomarkers of sepsis in critical care. J Antimicrob Chemother 2011, 66(Suppl 2):ii33-40.

46. Colonna M, Facchetti F: TREM-1 (triggering receptor expressed on myeloid cells): a new player in acute inflammatory responses. $J$ Infect Dis 2003, 187(Suppl 2):S397-401.

47. Tessarz AS, Cerwenka A: The TREM-1/DAP12 pathway. Immunol Lett 2008 116:111-116.

48. Cavaillon JM: Monocyte TREM-1 membrane expression in non-infectious inflammation. Crit Care 2009, 13:152.

49. Ferat-Osorio E, Wong-Baeza I, Esquivel-Callejas N, Figueroa-Figueroa S, Duarte-Rojo A, Guzman-Valdivia-Gomez G, Rodea-Rosas H, TorresGonzalez R, Sanchez-Fernandez P, Arriaga-Pizano L, Lopez-Macias C, RoblesDiaz G, Isibasi A: Triggering receptor expressed on myeloid cells-1 expression on monocytes is associated with inflammation but not with infection in acute pancreatitis. Crit Care 2009, 13:R69.

50. Bingold TM, Pullmann B, Sartorius S, Geiger EV, Marzi I, Zacharowski K Wissing $H$, Scheller B: Soluble triggering receptor on myeloid cells-1 (sTREM-1) is expressed in the course of non-infectious inflammation after traumatic lung contusion: a prospective cohort study. Crit Care 2011, R115.

51. Song F, Khan KS, Dinnes J, Sutton AJ: Asymmetric funnel plots and publication bias in meta-analyses of diagnostic accuracy. Int J Epidemiol 2002, 31:88-95.

doi:10.1186/cc11884

Cite this article as: Wu et al:: Accuracy of plasma sTREM-1 for sepsis diagnosis in systemic inflammatory patients: a systematic review and meta-analysis. Critical Care 2012 16:R229.

\section{Submit your next manuscript to BioMed Central and take full advantage of:}

- Convenient online submission

- Thorough peer review

- No space constraints or color figure charges

- Immediate publication on acceptance

- Inclusion in PubMed, CAS, Scopus and Google Scholar

- Research which is freely available for redistribution

Submit your manuscript at www biomedcentral com/submit
C Biomed Central 